\title{
Um Estudo do Estado da Arte Sobre a Utilização do Lúdico em Ensino de Química
}

\section{Games and Playful Activities in Chemistry Teaching: A National State of Art}

\author{
Edna Sheron da Costa Garcez ${ }^{\text {(i) }}$ Brasil \\ Márlon Herbert Flora Barbosa Soares Bi] Brasil
}

O presente trabalho apresenta um estudo bibliográfico das pesquisas acadêmicas desenvolvidas em jogos e atividades lúdicas no ensino de química no país. Analisamos produções acadêmicas de programas de pós-graduação, artigos de periódicos e publicações em congressos da área. Foram selecionados teses e dissertações do Banco de Teses da CAPES e da Biblioteca Digital de Teses e Dissertações do IBICIT; artigos dos periódicos: Química Nova, Química Nova na Escola, Revista Brasileira de Ensino de Química e Revista Brasileira de Pesquisa em Educação em Ciências; e trabalhos publicados nos Encontros Nacionais de Ensino de Química, nas Reuniões Anuais da Sociedade Brasileira de Química e nos Encontros Nacionais de Pesquisa em Educação em Ciências. Visando uma contribuição para a fundamentação teórica do lúdico na prática docente, primeiramente abordamos a natureza do jogo, apresentando inicialmente definições referentes ao termo jogo, seguido pelas teorias psicológicas baseadas em suas funções de finalidade biológica, no desenvolvimento cognitivo e psíquico do indivíduo, finalizando com as características formais sobre o jogo. Visualizando o quadro geral das produções e as características que têm se destacado em seu desenvolvimento, compreendemos que o campo de pesquisa sobre o lúdico no ensino de química ainda está em estruturação e necessita de um maior aprofundamento teórico, bem como de uma melhor compreensão do potencial do lúdico e a importância e necessidade de sua exploração frente a discussões e aprofundamentos teóricos no ensino e química.

Palavras-chave: Jogos e Atividades Lúdicas; Ensino de Química; Estado da arte.

This paper presents a bibliographic study of academic research undertaken about games and playful activities in chemical education in Brazil. We analyze academic productions of graduate programs, papers published in academic journals and conference publications in the area. We select theses and dissertations from the CAPES Collection of Theses and the IBICIT Digital Library of Theses and Dissertations; papers from the journals: Química Nova, Química Nova na Escola, Revista Brasileira de Ensino de Química and Revista Brasileira de Pesquisa em Educação em Ciências; and proceedings from the National Chemistry Teaching Meetings, Annual Meetings of the Brazilian Chemical Society and the National Research in Science Education Meetings. In order to contribute 
to the theoretical foundations of playfulness in teaching practice, we discuss the nature of games, by initially presenting definitions concerning the term game, followed by psychological theories based on their purposes related to biological, cognitive and psychological development of the individual functions. At the end, we discuss the formal features of the game. From an overview framework of the academic production in the area, and the characteristics that have been emphasized in its development, we view this research filed as still being structured. So, it requires further theoretical development as well as a better understanding of the potential of playful and the importance and need for their use to support discussions and theoretical insights in teaching and chemistry.

Keywords: Games and Playful; Chemistry Teaching; State of art.

\section{Introdução}

Uma das principais dificuldades no processo de ensino e aprendizagem é conseguir instigar o interesse do discente ao estudo. Com esta reflexão não queremos dizer o que está certo ou errado nos métodos de ensino. Destacamos apenas que se fazem necessárias alternativas metodológicas que resultem no aumento do interesse discente e sua motivação para o estudo. A escola tal como é apresentada aos nossos adolescentes é desinteressante e parece desconsiderar todo o seu convívio em sociedade. Nessa perspectiva, os professores são convidados a (re)pensar sua prática pedagógica, buscando assim promover um ensino mais atrativo de forma a conquistar e motivar o aluno para o estudo da ciência.

Considerando o Ensino de Química, ao observarmos as pesquisas na área, verificamos que diversas estratégias metodológicas têm sido propostas visando contribuir para a melhoria do processo de ensino e aprendizagem. Nos trabalhos apresentados em congressos da área, periódicos e pesquisas em nível de pós-graduação têm sido desenvolvidos inúmeros trabalhos procurando instigar o interesse do discente ao estudo, tais como, o uso da contextualização e da interdisciplinaridade, experimentação, materiais didáticos, leituras de textos avulsos, jornais e revistas, simulação, modelagem, analogias, redes sociais, entre outros. Nesse trabalho destacamos a utilização de atividades lúdicas como alternativas para o Ensino de Química, como uma forma de despertar o interesse dos discentes e motivá-los ao estudo de sua aprendizagem.

Dada a complexidade envolvida na definição de jogo e a dificuldade em sua conceituação, podemos identificar e reconhecer determinadas atividades como jogos, bem como atividades lúdicas, por meio das características culturalmente criadas, transmitidas e socializadas em determinado meio social. Resumidamente, o jogo pode ser descrito como uma atividade livre, consciente, não-séria, exterior a vida habitual, com desinteresse material e natureza improdutiva, que possui finalidade em si mesma, prazer (ou desprazer), caráter fictício ou representativo, com limitação no tempo e no espaço, com regras explícitas e implícitas (Brougère, 1998; Caillois, 1990; Huizinga, 
2000).

Na utilização do lúdico para o ensino de determinado conceito, por conta das características apresentadas anteriormente para os jogos, que são intrínsecas a qualquer atividade lúdica, observamos inúmeras desconfianças por parte da comunidade escolar. Aceita-se que tal ferramenta seja eficaz para a motivação discente, teoricamente se reconhece o potencial pedagógico deste recurso, entretanto, através dos discursos subtendidos e ações involuntárias, os atores deste processo expressam abertamente suas dúvidas relativas a aprendizagem conceitual com essa estratégia de ensino. É natural associar o estudo a uma atividade maçante, obrigatória e por muitas vezes indesejada. Levando em conta esses aspectos, é compreensível a resistência em associar-se com o lúdico que, ao contrário, sinaliza divertimento, prazer e alegria.

$\mathrm{O}$ aprender pode (e deve) ser uma ação divertida e prazerosa. De acordo com Soares (2013), o aprender pode ser uma brincadeira, e na brincadeira pode-se aprender, sendo função do professor promover tal forma de abordagem dos conteúdos da química. Entretanto, utilizar o lúdico como alternativa metodológica não é uma opção trivial, como se fosse um passatempo ou intervalo no Ensino de Química, sendo necessários a dedicação e o preparo docente. Requer que o professor tenha conhecimento de suas teorias, métodos e de seu potencial pedagógico, para que conscientemente e deliberadamente possa explorar as habilidades e competências que tais atividades podem propiciar ao estudante.

No Ensino de Química, observamos que é recente a utilização de jogos, conforme apresentado em uma revisão bibliográfica sobre a temática por Soares (2013). Os trabalhos mais antigos em revistas datam do final da década de 70. Citamos por exemplo, no Brasil, Rocha-Filho (1996) e Beltran (1997), publicados na revista Química Nova na Escola, o primeiro apresenta um material para construção da molécula buckminsterfulereno, já o segundo, desenhos animados para representar a solvatação e estados físicos da água. Há também três referências na revista Química Nova, a de Magalhães em 1978, que apresenta um jogo de cartas para ensino de reações orgânicas, em 1982 de Nicodem, que também apresenta um jogo de cartas para ensino de ressonância, e em 1993, de Craveiro e colaboradores, onde apresentam um jogo de tabuleiro do tipo perfil para identificação de elementos químicos e compostos orgânicos.

Dada a importância da utilização do lúdico para o ensino de química e sua crescente utilização conforme observada em eventos da área (Soares, 2016), nesse presente estudo, tivemos como objetivo visualizar e diagnosticar o campo de pesquisa sobre o lúdico, no intuito de compreender como vêm se estruturando e disseminando as produções acadêmicas no território nacional. Para tal, realizamos uma pesquisa do tipo "estado da arte" (Megid Neto, 1999; Slongo \& Delizoicov, 2006), utilizando a abordagem qualitativa para compreensão das informações encontradas (Bogdan \& Biklen, 1994). 


\section{Método}

Tendo em vista mapear e avaliar a produção das pesquisas acadêmicas sobre o lúdico no Ensino de Química desenvolvidas no país, recorremos a modalidade de pesquisa caracterizada como "estado da arte", utilizando a abordagem qualitativa para compreensão das informações encontradas, neste presente estudo, da natureza das produções apresentadas, as características gerais e as tendências verificadas nas produções escritas sobre a temática em estudo.

A abordagem qualitativa, tem se estendido à área das ciências sociais e das ciências humanas. As primeiras pesquisas com esse viés, no campo educacional, foram desenvolvidas a partir da década de 60 , período em que eram preponderantes as abordagens quantitativas dos fenômenos em estudo. Nessa abordagem, busca-se compreender a dinâmica do fenômeno em estudo analisando o contexto em que ocorre e do qual faz parte, por meio das significações para as pessoas nele envolvidas (Godoy, 1995; Ludke \& André, 1986).

Nos últimos anos, temos observado um aumento significativo nas produções denominadas "estado da arte" em todas as áreas do conhecimento, com o intuito de mapear e avaliar determinado campo de pesquisa. São também denominadas de pesquisas bibliográficas, de revisão ou de "estado do conhecimento", cujo material de análise são documentos escritos e/ou produções culturais obtidos em arquivos e acervos (Fiorentini \& Lorenzato, 2006).

As pesquisas do tipo estado da arte procuram descrever o estado atual de uma determinada área de pesquisa, constituindo-se em uma excelente fonte de atualização para o campo de pesquisa da área e/ou tema em estudo (Luna, 2011), pois, condensam os tópicos mais importantes do problema desta área e/ou tema em estudo e, geralmente, apresentam além do que já se conhece, as principais lacunas e os entraves teóricos e/ ou metodológicos. Haddad (2002) destaca que essas pesquisas permitem reconhecer temáticas e abordagens dominantes e emergentes, assim como lacunas e campos inexplorados, disponíveis a pesquisas futuras. Além destas características, apresentam um caráter inventariante, que por meio da sistematização dos dados permite identificar, recuperar, classificar e descrever o tema em um determinado período de tempo.

Esse tipo de pesquisa passa por dois momentos. O primeiro consiste na interação do pesquisador com a produção acadêmica, por meio do levantamento de material, quantificação e identificação dos dados bibliográficos. No segundo momento, o pesquisador se questiona sobre o inventariar dessas produções, assim "imaginando tendências, ênfases, escolhas metodológicas e teóricas, aproximando ou diferenciando trabalhos entre si, na escrita de uma história de uma determinada área do conhecimento" (Ferreira, 2002, p.265).

Partindo desses princípios metodológicos, a primeira parte do trabalho envolveu a delimitação de nosso objeto de pesquisa, a utilização do lúdico no Ensino de Química. Cabe ressaltar que nosso intuito com essa pesquisa foi mapear como se tem dado a produção sobre a utilização do lúdico e não avaliar se as produções apresentadas 
apresentam ou não caráter lúdico, ou mesmo o potencial pedagógico das atividades realizadas. Dessa forma, utilizamos como critério para obtenção dos trabalhos a intencionalidade lúdica apresentada pelos autores. Assim, partindo do pressuposto que os trabalhos apresentados utilizaram atividades lúdicas. Não procuramos questionar, como observamos em alguns trabalhos sobre essa temática, se o trabalho analisado seria ou não lúdico conforme o conceito do termo. Partimos do princípio, que, se o autor considera seu trabalho lúdico, em nosso estudo, também foi enquadrado como tal.

Tendo como referência os critérios para a construção de uma pesquisa do tipo estado da arte presente nas pesquisas realizadas por Megid Neto (1999) e Teixeira (2006), determinamos o período de revisão e as fontes para coleta de dados conforme o tipo de produção analisada (teses e dissertações, artigos e trabalhos em eventos).

A obtenção dos trabalhos realizou-se a partir do levantamento e seleção das produções, tendo como critério as palavras-chave uma série de palavras-chave correlatas ao tema, entre elas: atividade lúdica, lúdico, ludicidade, ludismo, brincar, brinquedo, brincadeira, diversão, divertido, jogo, jogo pedagógico/ didático/ educativo/ eletrônico/ virtual, games, história em quadrinhos, teatro, música e suas variações no plural além de seus cruzamentos com os termos educação, ensino, química e com as expressões e/ para o/no Ensino de Química.

Para o levantamento de dissertações e teses foram examinados: o Banco de Teses da Capes (Período 1987-2012), a Biblioteca Digital de Teses e Dissertações do Instituto Brasileiro de Informação em Ciências e Tecnologia (Período 1970-2014) e Catálogos Analíticos sobre o Ensino de Ciências (1972-2008), Ensino de Física (1972-2006) e Ensino de Biologia (1972-2008) produzidos pela Universidade Estadual de Campinas e pela Universidade de São Paulo. Buscando recuperar e identificar as pesquisas sobre o lúdico no ensino de ciências em programas de pós-graduação stricto sensu, o período de análise escolhido foi a data de sua criação até o ano de 2014, período correspondente ao término deste trabalho.

Os trabalhos apresentados em congressos da área foram analisados do período de 2000 a 2013. Delimitou-se o ano de 2000 para início da busca devido à dificuldade em obter acesso aos resumos de programa e anais de alguns eventos, seja em forma de livro ou CD-ROM. Nesta perspectiva, para possibilitar uma comparação quantitativa dos trabalhos apresentados definiu-se a mesma data de início para todos os congressos. Optamos por analisar os congressos da área de abrangência nacional, partindo do pressuposto que esse recorte possibilitaria uma boa visualização do campo de pesquisa em estudo. Foram selecionados resumos e trabalhos completos dos eventos: Encontro Nacional de Ensino de Química (ENEQ), Reunião Anual da Sociedade Brasileira de Química (RASBQ) e Encontro Nacional de Pesquisa em Educação em Ciências (ENPEC).

Averiguamos somente quatro dentre os periódicos disponíveis no sistema de estratificação de qualidade da produção intelectual da Capes. Foram selecionados artigos do acervo dos periódicos: Revista Química Nova (QN), Revista Química Nova na Escola (QNESC), Revista Brasileira de Pesquisa em Educação em Ciência (RBPEC) e 
Revista Brasileira de Pesquisa em Ensino de Química (ReBEQ). Estes periódicos foram selecionados por serem os mais importantes na área de ensino de química e ciências e por conterem, em uma primeira análise, artigos na área de jogos e atividades lúdicas. Analisamos os periódicos desde sua criação (QN - 1978; QNESC - 1995; RBPEC - 2001 e ReBEQ -2006) até o ano de 2014. Decidiu-se por essa data de início com o intuito de associar os resultados obtidos com as teses e dissertações recuperadas e identificados nos meios já citados.

\section{Seleção das Produções}

Para levantamento e seleção dos trabalhos nos questionamos: o que seria um trabalho lúdico? Como escolher os trabalhos apresentados se muitos autores relacionam atividades e/ou metodologias alternativas com propostas lúdicas? Os autores que trabalham com as diversas atividades lúdicas, de fato, reconhecem tal caráter? Partindo desses questionamentos, optamos por utilizar como critério de seleção a intencionalidade lúdica do autor. Poderíamos, como leitores, até reconhecer (e reconhecemos) alguns trabalhos vinculados ao campo de pesquisa do lúdico. Se o autor não reconhece o lúdico associado à sua proposta, como princípio ou elemento motivador para escolha da atividade desenvolvida, não selecionamos esse trabalho para nossa análise.

Conforme explicitado, o critério para escolha das produções foi a leitura dos resumos fornecidos pelo autor e a intencionalidade lúdica no desenvolvimento do trabalho. Assim, selecionamos aqueles que, no título ou no resumo, referenciassem ao lúdico, pois, entendemos que a referência a essas palavras tanto no título quanto no resumo expressavam a intencionalidade lúdica dos autores. Percebendo que a função didática em todos os trabalhos encontra-se destacada, procuramos, nas produções, referência ao lúdico. Também foram selecionados os trabalhos que apresentavam suas propostas tendo como justificativa da estratégia desenvolvida o ludismo relacionado a elas.

\section{Tratamento das Informações}

A partir da lista dos trabalhos selecionados, obtivemos suas cópias integrais, para realização, em um primeiro momento, da sistematização dos dados bibliográficos e alguns aspectos pedagógicos dos textos. Os dados bibliográficos catalogados foram: autor(es), título, instituição e palavras-chave. Para as dissertações e teses também foram descritos os itens: tipo de produção, ano de defesa, orientador e programa de pós-graduação. Já para os trabalhos publicados em eventos e em artigos de periódicos, acrescentou-se: tipo de evento/periódico e ano do evento/artigo. Os aspectos pedagógicos catalogados foram conteúdo/tema, tipo de atividade lúdica, nível de ensino, sujeitos da pesquisa e resultados.

\section{Dimensões de Análise}

As informações obtidas a partir da sistematização dos dados bibliográficos e 
pedagógicos das dissertações, teses, artigos e trabalhos de eventos foram analisadas em três dimensões. As duas primeiras foram definidas a priori, com base nos descritores estabelecidos por Megid Neto (1999), e foram denominadas Aspectos Gerais e Aspectos Pedagógicos. A terceira emergiu da leitura das informações, denominada Natureza dos Trabalhos.

Neste artigo apresentamos de forma sumarizada os aspectos formais e pedagógicos derivados da sistematização, discutindo de forma mais aprofundada a dimensão que emergiu da leitura das informações: a natureza das produções acadêmicas analisadas, denominada para fins de análise: Natureza dos Trabalhos.

A primeira dimensão, Aspectos Gerais, tem relação com os dados bibliográficos dos trabalhos. Essa dimensão trabalha com os dados bibliográficos das produções, apresentando os aspectos formais que envolvem uma produção, tais como número de trabalhos, ano de produção, unidade federativa, instituição e associação com temáticas ou projetos de pesquisa dos autores. Por meio da relação entre os tipos de produção, número de trabalhos e ano de publicação é possível diagnosticar o crescimento da área. Já a sua distribuição e disseminação no país foi mapeada a partir da análise da relação das unidades federativas, instituição e associação com temáticas ou projetos.

Para obtenção dos valores apresentados, após a sistematização foram realizados cruzamentos entre os aspectos formais apresentados para verificar as possíveis relações estabelecidas entre tipo, ano e local de produção com o quantitativo de trabalhos apresentados por meio de tabelas e gráficos. Nesses, buscou-se caracterizar o quadro geral de produções conforme foi sendo desenvolvido no país. Vale ressaltar que, após esse entrelaçamento dos aspectos, os valores apresentados foram obtidos por meio da contagem e as porcentagens por meio das proporções entre as características abordadas.

Na segunda dimensão, Aspectos Pedagógicos, analisamos os aspectos referentes à proposta pedagógica apresentada pelos autores. Foram abordados os seguintes fatores: nível de ensino, conceitos trabalhados e tipo de atividade lúdica desenvolvida, relacionados à aplicação e estruturação da atividade. A partir desses itens foi possível verificar os aspectos que têm sido priorizados nas propostas pedagógicas e aqueles que são poucos desenvolvidos ou mesmo inexplorados, possibilitando, assim, visualizar como se tem dado a utilização do lúdico no Ensino de Química. Assim, como nos aspectos formais, foram realizados cruzamentos entre os aspectos pedagógicos por meio de tabelas e gráficos a fim de obter dados quantitativos das produções e possíveis padrões entre as produções ou mesmo identificar diferenças marcantes entre as produções de uma região ou de um período. Nessa dimensão, um mesmo trabalho somou ao quantitativo de diferentes aspectos. Por exemplo, em sua proposta teve como público alvo o ensino médio e o ensino fundamental, de forma que, na maioria das vezes, a somatória dos valores apresentados é superior à quantidade de produções analisadas.

A terceira dimensão, Natureza dos Trabalhos, apresenta algumas características referentes às produções acadêmicas (apenas os artigos de periódicos e trabalhos apresentados em eventos). Por meio delas é possível verificar os aspectos abordados pelos 
autores em sua escrita. Isso possibilita inferir as tendências da produção acadêmica sobre o lúdico no Ensino de Química. Essa dimensão aborda o direcionamento das propostas, os resultados e discussão das propostas pedagógicas apresentadas e a fundamentação teórica utilizada, além de quais abordagens têm sido dominantes e emergentes no campo de pesquisa, bem como as lacunas e os problemas da área oriundos da ausência ou pouca fundamentação teórica sobre o lúdico, sua intersecção tanto com o campo educacional quanto com a química. Para catalogação dos aspectos abordados nessa dimensão, foi identificada uma única categoria para cada trabalho.

No descritor resultados e discussão, não foram realizados tratamento estatísticos, porque muitas vezes no texto o autor utilizou várias abordagens para descrever e analisar a função do lúdico nos resultados descritos na proposta, não permitindo identificar a forma predominante. Nesse aspecto foram elencadas as abordagens observadas no texto e a função do lúdico nas propostas discutidas como: avaliação da atividade lúdica aplicada com base na sua eficácia e/ou aceitabilidade como instrumento de ensino analisando aspectos quantitativos e qualitativos como análise das concepções relacionadas à sua utilização, instrumentação na formação docente, na divulgação científica entre outros.

No último aspecto desta dimensão, fundamentação teórica, é feita uma catalogação das referências utilizadas pelos autores em seus respectivos trabalhos. Os valores foram obtidos por meio da contagem e porcentagens relativas às características observadas nos cruzamentos realizados entre obra, autor e temática da obra. Essa dimensão analisa a fundamentação teórica utilizada para apresentação e discussão das atividades lúdicas aplicadas, propostas/descritas, de cunho bibliográfico e teórico.

\section{Panorama Geral das Produções Acadêmicas}

No levantamento realizado sobre a temática, encontramos 398 produções acadêmicas relativas a utilização do lúdico no ensino de química, conforme apresentado no Quadro 1.

Quadro 1. Distribuição da Quantidade de Trabalhos por Tipo de Produção Acadêmica

\begin{tabular}{|c|c|c|c|}
\hline \multicolumn{2}{|l|}{ Produções Acadêmicas } & Período de Análise & Quantidade \\
\hline \multirow{3}{*}{ Pós Graduação } & Doutorado & \multirow{3}{*}{$1972-2014$} & 4 \\
\hline & Mestrado Acadêmico & & 13 \\
\hline & Mestrado Profissionalizane & & 5 \\
\hline \multirow{4}{*}{ Periódicos Científicos } & Química Nova & $1978-2014$ & 5 \\
\hline & Química Nova na Escola & 1995-2014 & 20 \\
\hline & RBPEC & 2001-2014 & 1 \\
\hline & ReBEQ & 2016-2014 & 5 \\
\hline \multirow{3}{*}{ Eventos Científicos } & ENEQ & \multirow{3}{*}{$2000-2014$} & 204 \\
\hline & RASBQ & & 124 \\
\hline & ENPEC & & 17 \\
\hline & & TOTAL & 398 \\
\hline
\end{tabular}

Identificamos 398 produções acadêmicas, sendo essas distribuídas em 22 trabalhos de dissertações e teses, 31 de artigos e 345 de resumos e trabalhos completos. 
A partir do levantamento realizado nos Catálogos Analíticos desde o ano de 1972, identificamos que primeiro trabalho sobre o lúdico no Brasil foi uma dissertação de mestrado, defendida em 1988, por Eugênio Maria França, hoje, professor da UNESP, e a primeira tese de doutorado, defendida em 1993, ambas na área de Ensino de Física.

Analisando a distribuição das teses e dissertações por ano de defesa para a área de ensino de química, observa-se na Figura 01 que a primeira produção em nível de pesquisa em pós-graduação se refere a uma tese, defendida em 2004.

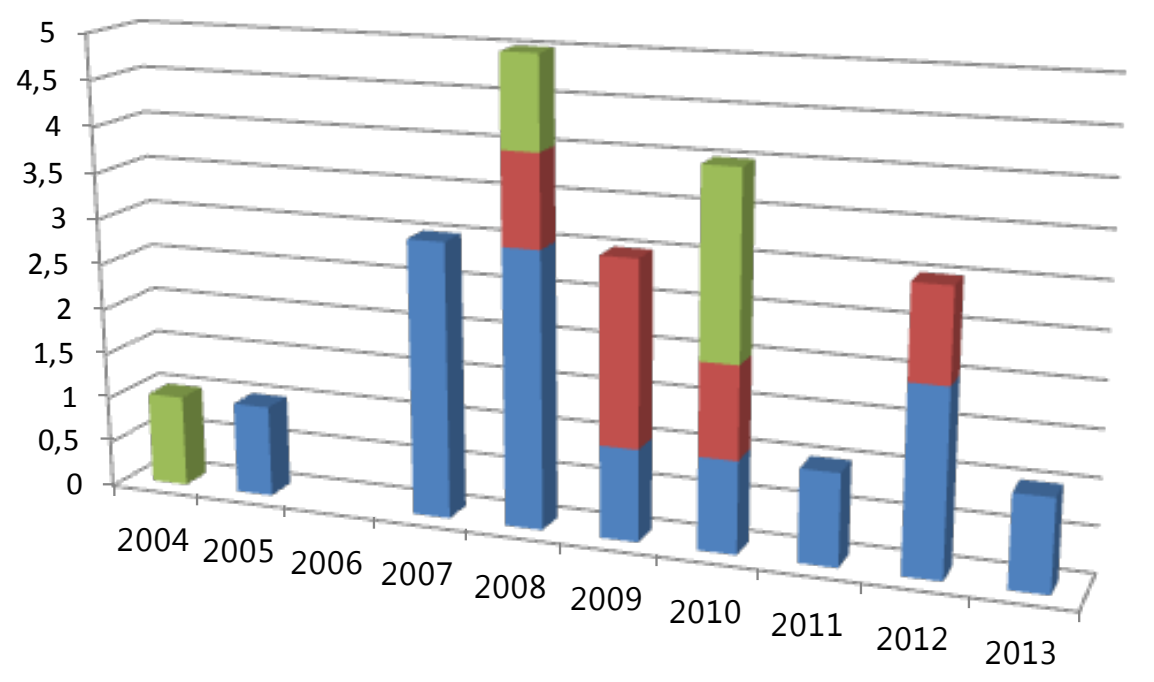

- Mestrado Acadêmico $\square$ Mestrado Profissionalizante $\quad$ Doutorado

Figura 1. Distribuição das Teses e Dissertações em Química por Ano de Defesa

Essas produções subdividem-se em 13 dissertações de mestrado acadêmico, 05 dissertações de mestrado profissionalizante e 04 teses de doutorado. A partir de 2007, há um crescimento significativo das produções, sendo esse em parte relacionado a grupos de pesquisa que se dedicam ao estudo do lúdico no Ensino de Química. Dessas produções, 11 estão vinculados a três orientadores, o que sinaliza a existência de grupos de pesquisa sobre o tema, na UFG, em Goiás sob a supervisão do prof. Márlon Herbert Flora Barbosa Soares; na USP, em São Paulo sob a supervisão da profa. Daisy de Brito Resende; e na UENF, no Rio de Janeiro sob a supervisão da profa. Rosana Aparecida Giacomini.

Encontramos 31 artigos nos periódicos analisados. A Figura 2 apresenta a distribuição dos artigos conforme o ano de publicação. O primeiro artigo foi publicado na Revista Química Nova em 1978 e trata-se de uma nota técnica apresentando um jogo de cartas como estratégia para o ensino de reações químicas na disciplina de Química Orgânica. A partir de 2005, verificamos um aumento na produção, apresentando no ano de 2012 a maior quantidade de artigos. A participação da QNESC é preponderante aos outros periódicos analisados; sendo, de maneira geral, pouca a produção acadêmica.

Observa-se que há uma diferença do nível de ensino trabalhado conforme o público alvo da revista. Os artigos veiculados pela QNESC e ReBEQ direcionam- 
se a professores e pesquisadores da área de Ensino de Química e a RBPEC ao Ensino de Ciências. Esses três periódicos como estão relacionados com a educação básica, apresentam artigos, em sua maioria, voltados para o nível médio e fundamental. Já a QN volta-se a um público de pesquisadores em Química, apresentando artigos que discutem ensino, geralmente, voltados para o nível universitário.

Uma característica observada na maioria dos artigos, excetuando-se aqueles da QN, é apresentarem referências ao lúdico. Essas falas se restringem a uma breve revisão bibliográfica, apresentação das características intrínsecas ao lúdico ou definição de jogo educativo. Raramente apresentam uma fundamentação teórica mais elaborada, entretanto, seja em um breve parágrafo ou em subtítulo, a maioria dos artigos faz citação à utilização do lúdico no ensino.

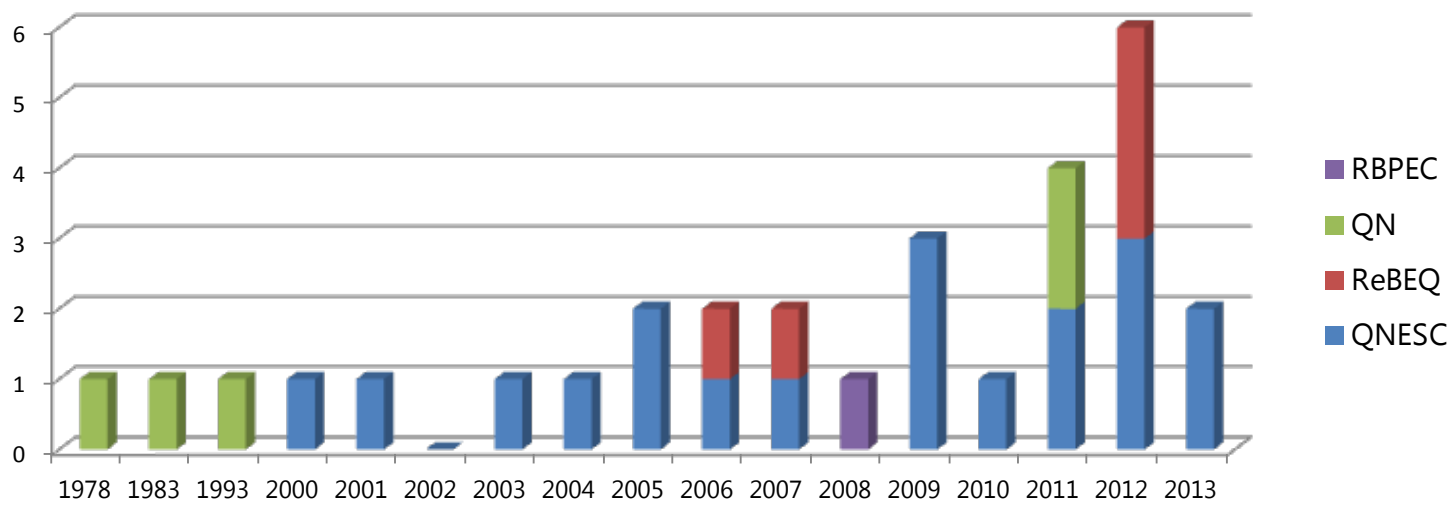

Figura 2. Produção sobre o Lúdico por Ano e por Periódico

Há 345 trabalhos publicados em eventos, sendo 204 referentes ao ENEQ, 124 à RASBQ e 17 ao ENPEC. Desses trabalhos, 58 correspondem a trabalhos completos (41ENEQ e 17-ENPEC) e 287 a resumos (163-ENEQ e 124-SBQ). Na Figura 3, observa-se a produção sobre o lúdico por ano e por evento. Podemos perceber o crescimento linear de trabalhos no ENEQ, já na SBQ observa-se que não há um padrão de crescimento na produção sobre o lúdico. Quanto ao ENPEC, ainda é cedo para averiguar a taxa de produção, já que o evento é bienal e é recente a produção sobre o lúdico na área de ensino de Química neste evento.

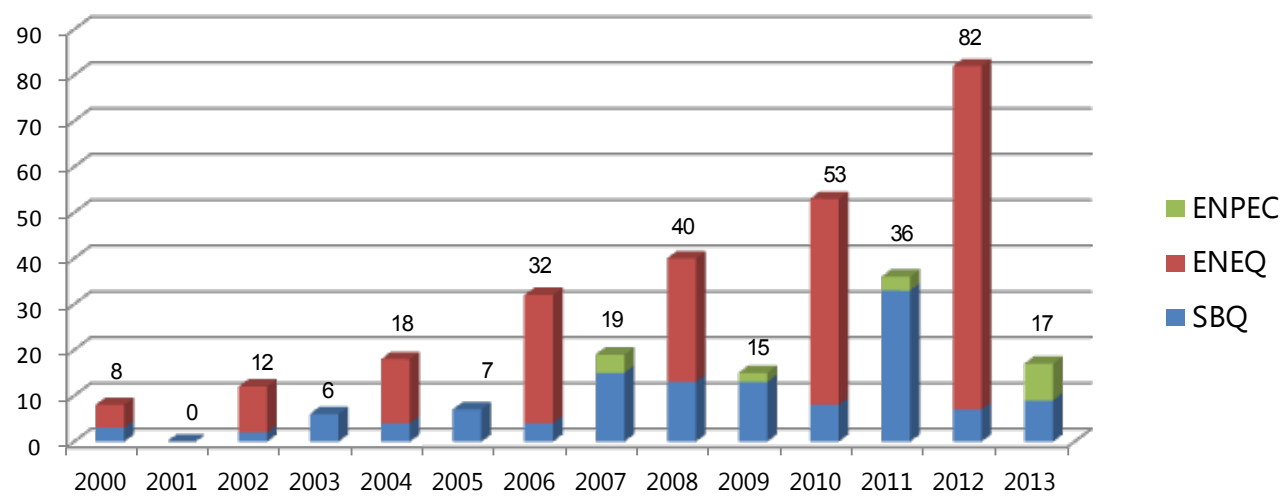

Figura 3. Produção sobre o Lúdico por Ano e Evento 
Esses trabalhos apresentam em comum a estruturação da proposta desenvolvida. Geralmente, apresentam a produção escrita em termos das características intrínsecas ao lúdico, seguindo-se o objetivo e a turma em que foi aplicada. Subdividem-se em trabalhos de aplicação e de pesquisa em ensino, sendo poucos os trabalhos voltados à área da pesquisa. Em sua maioria, os trabalhos são produções que envolvem aplicações em sala de aula, descrevendo o desenvolvimento da atividade, avaliando subsequentemente a eficácia da atividade.

Relativo aos aspectos pedagógicos dos trabalhos publicados nos eventos, quanto ao nível de ensino, observamos que a maioria dos trabalhos são propostas ao ensino médio (160), seguido pelo ensino superior (63) e pelo ensino fundamental (38). Embora, a química seja uma disciplina específica do nível médio de ensino, ela não se restringe a essa modalidade da educação. Precisa se incentivar trabalhos que procurem ambientar suas pesquisas em territórios desconhecidos, como por exemplo, voltados para a educação infantil, educação popular, educação de jovens e adultos, educação indígena, entre outros. Tal exploração seria riquíssima na construção de novos saberes, sendo necessária não apenas para o campo de lúdico, mas no desenvolvimento da área de Ensino em Química, já que observamos que as pesquisas da área permanecem nesse estado estacionário de nível de ensino.

Com relação às áreas abordadas, observamos que 102 trabalhos estão relacionados a temáticas, 26 apresentam conteúdos diversos e 53 trabalham de forma geral "química". Quanto à divisão dos conteúdos conforme o currículo do estado do ensino médio, observamos que 194 trabalhos são de química geral, 61 referentes a química orgânica e 43 de físico-química. Os conceitos mais explorados são relativos à tabela periódica e aos elementos químicos, ácidos e bases, compostos inorgânicos, nomenclatura e função orgânica. Isso sugere ou que tais conteúdos são frequentemente abordados porque são mais fáceis de serem trabalhados e/ou por que os discentes possuem muita dificuldade na compreensão da química apresentada no primeiro ano, justificando assim a grande produção relacionada à química geral.

Referente à distribuição dos trabalhos pelos tipos de atividades lúdicas, observase uma maior exploração dos jogos de tabuleiro (94) e de cartas (63). Nos jogos de tabuleiro, incluem-se aqueles do tipo corrida, ludo, trilha, perfil, campo minado, entre outros. Essas atividades são seguidas por experimentação (37), bingo (28), materiais manipuláveis (25) e jogos teatrais/júri simulado (23). Relativo a essa escolha das atividades lúdicas, observamos que ao mesmo tempo em que há uma diversificação de propostas, simultaneamente há o predomínio de jogos de cartas e de tabuleiro, prioritariamente os do tipo trilha. Isso se deve ao fato desses tipos de jogos serem comuns em nosso país, assim, mais familiares tanto aos discentes quanto aos docentes. Consequentemente, mais fácil sua aplicação. O tempo de execução e o espaço para desenvolvimento de algumas atividades, também justificam a escolha por jogos de cartas e de tabuleiro, entretanto, é importante uma maior diversificação nas propostas apresentadas. 


\section{Relação dos trabalhos publicados em periódicos e eventos com as produções de pós-graduação}

No levantamento realizado, como expresso anteriormente, encontramos 22 teses e dissertações sobre a utilização do lúdico em ensino de Química. Com o intuito de diagnosticar o campo de pesquisa sobre o tema em estudo relacionamos os artigos publicados nos periódicos e os trabalhos apresentados nos eventos as teses e dissertações elencadas no Quadro 01. Dessa forma, no Quadro 02 visualizamos a quantidade de trabalhos oriundos das produções a níveis de pós-graduação identificadas na pesquisa realizada.

Por meio do Quadro 2 é possível verificar que apenas 14,4\% dos trabalhos em congressos e periódicos são oriundos das pesquisas realizadas em nível de pósgraduação. Observa-se que o percentual de trabalhos apresentados nos congressos derivados das pesquisas, não corresponde nem a $25 \%$ da produção total de cada evento. A coluna \% de trabalhos vinculados, no Quadro 2, associa a quantidade de produções que são oriundas de pesquisas de pós-graduação à quantidade total de trabalhos para cada tipo de evento/periódico apresentado no Quadro 1, sendo que no ENEQ, RASBQ e ENPEC estão vinculados respectivamente, apenas 10,8; 17,7 e 23,5 \% dos trabalhos apresentados.

Quadro 2. Relação dos Eventos e Periódicos com as Produções dos Programas de Pós-

Graduação

\begin{tabular}{|c|c|c|c|c|c|}
\hline $\begin{array}{c}\text { Eventos/ } \\
\text { Periódicos }\end{array}$ & Doutorado & $\begin{array}{c}\text { Mestrado } \\
\text { Acadêmico }\end{array}$ & $\begin{array}{c}\text { Mestrado } \\
\text { Profissionalizante }\end{array}$ & Produções & $\begin{array}{c}\text { \% Trabalhos } \\
\text { Vinculados }\end{array}$ \\
\hline ENEQ & 9 & 13 & 0 & 22 & 10,8 \\
\hline RASBQ & 9 & 13 & 0 & 22 & 17,7 \\
\hline ENPEC & 0 & 4 & 0 & 4 & 23,5 \\
\hline QN & 0 & 0 & 0 & 0 & 0,0 \\
\hline QNESC & 2 & 3 & 0 & 5 & 25,0 \\
\hline RBPEC & 0 & 1 & 0 & 1 & 100,0 \\
\hline ReBEQ & 0 & 0 & 0 & 0 & 0,0 \\
\hline Total & 20 & 34 & 0 & 54 & 14,4 \\
\hline
\end{tabular}

Dos 345 trabalhos apresentados em eventos, apenas 48 estão vinculados aos trabalhos de pós-graduação sendo 18 resultantes de projetos de doutorado e 30 de mestrado acadêmico, valor que corresponde a um percentual de 13,9\%. Observa-se que o percentual de trabalhos apresentados nos congressos derivados das pesquisas, não corresponde nem a $25 \%$ da produção total de cada evento.

Do total de 22 dissertações/teses que trabalham a temática do lúdico, somente 6 redundaram em artigos científicos nas revistas especializadas analisadas. Dos quatro periódicos analisados (QN, QNESC, RBPEC e ReBEQ): 1 trabalho proveniente de um mestrado acadêmico publicado na RBPEC e 5 trabalhos publicados na QNESC, sendo 2 produções derivada do doutorado e 3 oriundas do mestrado acadêmico. Observa-se 
também que dos 31 artigos publicados sobre o lúdico em ensino de química, apenas os seis, citados anteriormente, estão vinculados as pesquisas em nível de pós-graduação, corresponde a $19,4 \%$. Tal resultado leva-nos a refletir sobre qual o produto derivado das pesquisas realizadas em nível de pós-graduação, em qual meio elas são socializadas ou mesmo o que impulsionou a produção do outros artigos que não se encontram associados à pesquisas de pós-graduação.

Os percentuais, de 13,9\% para eventos e 19,4\% para artigos de periódicos sinalizam que a associação dos trabalhos com a pesquisa de pós-graduação ainda é pequena. Cabe ressaltar, que essa porcentagem está relacionada aos eventos e periódicos analisados, sendo que os autores podem ter optado por outro meio de comunicação e socialização de sua pesquisa. Entretanto, mesmo tendo em perspectiva a consideração descrita, é possível inferir que esses resultados permitem visualizar que o campo de pesquisa se encontra em fase de crescimento, sendo necessário para sua consolidação uma maior associação dos trabalhos produzidos a projetos de pesquisa em nível de pós-graduação. Tal associação se faz primordial para que estes possuam embasamento teórico-metodológico sobre o lúdico no Ensino de Química e não se constituam apenas em trabalhos isolados de aplicações individuais em cada instituição.

Outro dado que o Quadro 2 nos apresenta é relativo à produção derivada por tipo de pesquisa em nível de pós-graduação (doutorado, mestrado acadêmico e mestrado profissionalizante). Observamos que 20 produções são oriundas de 4 teses de doutorados e 34 produções de 13 dissertações de mestrados acadêmicos, não havendo produção relacionada ao mestrado profissionalizante, o que gera uma média de 5 trabalhos por tese e 2,5 trabalhos por dissertação. Considerando o tempo da pesquisa e o volume de material coletado, esperava-se uma maior produção do pós-graduando.

A partir desses resultados encontrados realizamos uma busca das produções derivadas das pesquisas em níveis de pós-graduação a partir do Currículo Lattes dos 22 autores. Verificamos que os autores que não contribuíram para a produção em nível nacional nas fontes de buscas selecionadas para essa pesquisa, apresentaram em seus Currículos Lattes comunicação e socialização de seus trabalhos em eventos locais e regionais. Observamos que há publicação das pesquisas na forma de livros ou de capítulos de livros e em outros periódicos que neste trabalho não foram contemplados, tais como: Cadernos Temáticos, Experiência no Ensino de Ciências, Revista Didática Sistêmica, Revista Areté, Revista Electrónica de Investigación en Educación en Ciencias, Revista Electrónica de Enseñanza de las Ciencias, entre outros. Enfim, houve uma socialização dos trabalhos na forma de artigo em outras revistas, não analisadas nesse trabalho, no entanto, salientamos que esses trabalhos também estão relacionados aos mesmos autores descritos anteriormente.

\section{Natureza das Produções Acadêmicas}

Ao tratarmos da natureza geral dos trabalhos publicados, estamos nos referindo às características e tendências observadas nas escritas das produções. Nessa dimensão 
de análise, trabalhamos somente os artigos de periódicos e os trabalhos apresentados nos eventos. Nesse caso, analisamos 376 do que chamaremos de Produções Acadêmicas (PA). Dessa forma, codificamos e ordenamos tais produções por ordem alfabética de título e os numeramos. Cada trecho selecionado e analisado a seguir será identificado pela sigla PA e seu respectivo número.

Por meio desses descritores, é possível delinear o campo de pesquisa e identificar as tendências nas produções acadêmicas. Através dos aspectos elencados podemos inferir quais abordagens têm sido dominantes e emergentes no campo de pesquisa sobre o lúdico no Ensino de Química, bem como as lacunas e os problemas da área oriundos da ausência ou pouca fundamentação teórica sobre o lúdico e sua intersecção tanto com o campo educacional quanto com a química. A seguir, apresentaremos as características observadas nas produções. Estes aspectos correspondem aos direcionamentos da proposta, a forma de apresentar seus resultados e discussão, a exploração da fundamentação teórica nas produções.

\section{Natureza dos Trabalhos - Direcionamento da Proposta}

O primeiro descritor refere-se ao direcionamento da proposta realizada, isto é, à forma que o autor aborda a proposta, conduzindo sua pesquisa e analisando seus resultados. Por meio desta, procuramos compreender a forma e identificar o direcionamento que o autor escolheu para expressar e apresentar sua proposta. Nas produções analisadas encontramos sete tipos de abordagens, que são: relatos de experiência, divulgação científica, formação docente, concepção/opinião, teórico, revisão bibliográfica e proposta/descrição. Destes trabalhos um percentual de $8,8 \%$, apresentam propostas relacionadas a pesquisa em Ensino de Química envolvendo o ludismo, estas correspondem aos trabalhos de concepção/opinião, teórico, revisão bibliográfica e proposta/descrição.

A maioria das produções acadêmicas são trabalhos de relatos de experiências, correspondendo a 58,5\% dos trabalhos. Os relatos de experiência são textos que apresentam aplicações de atividades lúdicas, dialogando com o leitor as experiências vivenciadas, tais como as dificuldades apresentadas e as respostas obtidas com essa estratégia de ensino. De forma geral, o formato dessas produções envolvem a aplicação de atividades lúdicas, com posterior avaliação, seja da atividade proposta ou da aprendizagem propiciada, conforme expresso anteriormente. No relato da aplicação, se apresenta o público alvo, o conteúdo a ser abordado, os objetivos almejados com a atividade, seguidos por uma descrição detalhada de cada etapa da aplicação. À medida que os autores apresentam o desenvolvimento da atividade, discutem o resultado obtido com a aplicação, discorrendo sobre as impressões dos alunos, as dificuldades encontradas e o desempenho discente.

Os trabalhos que se direcionam a explorar a Divulgação Científica correspondem a 5,1\%. Embora sejam relatos de experiência, apresentam como foco trabalhos cuja abordagem visa a divulgação e disseminação da ciência, seja no meio escolar ou na 
comunidade. Apresentam estrutura similar aos relatos de experiências, mas, nesses, a ênfase da proposta desenvolvida é a divulgação científica. A partir dos experimentos, jogos e outros tipos de atividades executados, os autores apresentam a química procurando desmistifica-la e aproximá-la do cotidiano do público.

Os trabalhos elencados em Formação Docente correspondem a 5,9\% das produções. Nesses, observamos a relação existente entre o ludismo e a formação docente. Apresentam o lúdico como estratégia didática para a formação inicial ou continuada do professor de química ou sua utilização como atividade de ensino para o licenciando. São poucos os trabalhos relacionados à Concepção/Opinião, correspondendo a 2,9\%. Esses trabalhos dedicam-se a interpelar sobre o significado das atividades lúdicas para os discentes, seja de nível médio, fundamental ou superior, averiguando suas opiniões e concepções sobre esse assunto.

Os trabalhos de cunho Teórico representam 2,9\% das produções. Esses trabalhos apresentam diálogo(s) entre o lúdico e outra(s) área(s) do conhecimento. São também pertencentes a essa abordagem as propostas que apresentam referenciais ou aspectos teóricos sobre o uso de jogos ou utilizam teóricos da educação para discutir o lúdico. Nas produções publicadas, as discussões apresentadas como 'cunho teórico' estabelecem relação entre oludismo e a experimentação, ludismo e avaliação da aprendizagem, ludismo e as funções psicológicas superiores e abordagem aspectos teóricos e metodológicos sobre a aplicação de atividades lúdicas no Ensino de Química. Contribuindo, assim, para a formação de um arcabouço teórico e metodológico para o campo de pesquisa.

As propostas de Revisão Bibliográfica correspondem a 2,4\% dos trabalhos. Embora possam ser consideradas também de cunho teórico, destacamos este tipo de abordagem, pois, apresentam especificamente análises sobre produções publicadas com o tema em estudo. As produções elencadas em Proposta/Descrição representam 9,6\% dos trabalhos. Nesses, apresenta-se propostas para o ensino da química. Por meio da descrição das atividades lúdicas, apresentam sua estrutura, objetivo, regras, bem como sugestões para sua confecção e aplicação. Visando um bom aproveitamento da atividade alguns trabalhos também descrevem suas limitações e possibilidades pedagógicas.

\section{Natureza dos Trabalhos - Resultados e Discussão}

No descritor, resultados e discussão, apresentamos as formas de abordagem observadas nas produções para descrever e analisar os resultados obtidos nas propostas realizadas. Em sua maioria, as produções apresentam os resultados com base na avaliação da atividade. $\mathrm{O}$ avaliar é uma necessidade no processo de ensino e aprendizagem, tanto para o professor quanto para o aluno. Por meio da avaliação o professor pode acompanhar o processo de aprendizagem de seus alunos, verificar os conhecimentos que possui, suas dificuldades e em que aspectos ele tem que melhorar, bem como os aspectos em que o professor precisa aperfeiçoar a prática docente. A avaliação apresentada nos resultados corresponde ora à eficácia e aceitabilidade da atividade lúdica como instrumento de ensino, ora à aprendizagem dos alunos, seja em seu aspecto afetivo, social, psíquico ou 
cognitivo.

Os resultados das produções são descritos em função da aplicação de uma atividade lúdica ou da pesquisa realizada relacionada à temática. Os trabalhos que relatam aplicação apresentam discussões relacionadas ao seu uso em sala de aula ou na divulgação científica. Os trabalhos de pesquisa em ensino apresentam discussões relacionadas ao direcionamento da pesquisa realizada: revisão bibliográfica, teórico, proposta/descrição.

Os trabalhos que desenvolveram revisão bibliográfica sobre o lúdico no Ensino de Química apresentam em suas discussões análise sobre as produções já publicadas em eventos da área. São pesquisas, de acordo com Luna (2011) que procuram "mostrar através da literatura publicada o que já sabe sobre o tema, quais as lacunas existentes $e$ onde se encontram os principais entraves teóricos e metodológicos" (Luna, 2011, p. 30) Apresentam aspectos relacionados à quantidade e distribuição das produções por ano, evento, estado, conteúdo, tipo de atividade lúdica, tema em estudo, entre outros. No exemplo a seguir, temos um estudo bibliográfico sobre os níveis de cognição nos trabalhos publicados sobre jogos em Ensino de Química:

Foram pesquisados em vários periódicos artigos que tratavam do uso de atividades lúdicas no Ensino de Química [...] o ano da publicação da primeira experiência para ensinar ciências remonta ao ano de 1929 [...] as publicações a nível nacional se concentraram nos últimos 10 anos e que essas publicações envolvem níveis de cognição mais elevados do que os publicados em periódicos internacionais [...] (PA342)

$\mathrm{Na}$ discussão sobre os trabalhos de cunho teórico, encontramos análises que discorrem sobre o tema proposto relacionando os jogos com teorias de outra área do conhecimento. Há, nessa abordagem, propostas que apresentam discussões sobre referenciais teóricos e metodológicos relativos ao uso de jogos, assim como teóricos da educação dialogando com o lúdico. Como exemplo, apresentamos a discussão sobre a utilização do jogo como instrumento de avaliação da aprendizagem:

O uso do lúdico em sala de aula permite que a relação professor-aluno torne-se mais efetiva [...] tornando mais fácil identificar as dificuldades e diferenças de cada um e com isso, podendo realizar o trabalho de diagnosticar possíveis falhas para posteriormente corrigí-las [...] Nesse aspecto, podemos inferir que o jogo apresenta características de uma avaliação do tipo diagnóstica [...] (PA237)

Nas pesquisas de proposta/descrição, verificamos que os resultados e discussão correspondem à apresentação de propostas lúdicas criadas e/ou adaptadas da atividade original para o Ensino de Química. Na discussão, observa-se a descrição da estrutura, objetivos, regras, conteúdo, possibilidades, limitações, entre outros. No trabalho a seguir, podemos observar a apresentação de um jogo:

O jogo IonizAÇÃO é voltado para o ensino médio, e pode ser jogado de 2 a 8 alunos. Contempla as áreas de Química Geral, Orgânica, Físico-Química e História da Química [...] No que condiz as regras explícitas, o objetivo dos jogadores é chegar ao centro do tabuleiro passando por quatro etapas: átomos neutros, cátions monovalentes, bivalentes 
e trivalentes. Para fazer a transição de uma etapa para outra, é necessário gastar certo valor de energia [...] No que condiz as regras implícitas está o conceito de EI e a sua dependência com o elemento em si [...] (PA074)

Os resultados descritos em função da aplicação da atividade lúdica apresentam como direcionamento em sua escrita a abordagem expressa pelo autor em sua pesquisa. De forma que a abordagem do resultado obtido pode ser a análise das concepções dos participantes quanto à utilização do lúdico, discussão sobre o lúdico na divulgação científica, avaliação do jogo proposto para o Ensino de Química, diálogo do lúdico com uma teoria educacional, considerações sobre o lúdico como recurso pedagógico e na instrumentação de professores em formação inicial e continuada em Química/Ciências, conforme apresentado, nas citações a seguir:

Para a realização desse estudo, foram entrevistados os professores [...] Foi constatado que a maioria dos entrevistados concorda que o uso de atividades lúdicas é de fundamental importância no ensino, no entanto, alguns se mostraram apáticos a sua utilização, acreditando poder haver interpretações errôneas entre o aprender e o brincar [...] (PA368)

a Casa da Descoberta investiu na montagem de uma bancada para a realização de experimentos simples e divertidos de Química para despertar o interesse do visitante de um modo geral [...] A popularização da Ciência é uma necessidade para o pleno exercício da cidadania [...] O uso de experimentos é uma metodologia que tem sido complementada pelo desenvolvimento de outras estratégias de ensino, como, por exemplo, o uso do lúdico em jogos como o Quis da Casa da Descoberta, Bingo de Ciências, e brincadeiras de mágicas [...] (PA039)

Tanto na aplicação no Ensino Médio quanto no Ensino Superior, os estudantes participaram ativamente e à medida que iam se familiarizando com a dinâmica da partida, iam demonstrando bastante interesse no jogo [...] A estrutura e dinâmica deste jogo, assim como a variação do nível de dificuldade programado permitem verificar se o estudante compreende o conteúdo e relaciona adequadamente a nomenclatura as fórmulas das substâncias inorgânicas estudadas. (PA113)

As atividades lúdicas que desenvolvemos se localizam no $2^{\circ}$ e $4^{\circ}$ patamar da pirâmide, onde os jogos envolvem segurança física e psicológica e a necessidade de auto-estima [...] Tapete periódico: é uma atividade situada no segundo patamar da pirâmide de Maslow, onde visa desenvolver a aplicação de conhecimentos e de memória, além do trabalho em grupo e de confiança e assertividade (PA224)

Ao término do curso de formação, os professores demonstraram-se motivados em continuar utilizando outros recursos lúdicos em suas aulas [...] (PA133)

As produções que apresentam avaliação da atividade aplicada possuem como formato, em sua maioria, um texto que se inicia com uma discussão em que se destaca a melhoria na aprendizagem, seguida de uma avaliação. Essa avaliação geralmente é 
realizada por meio do desempenho dos alunos, apresentando ora a sua aprendizagem por meio do desenvolvimento de atividades lúdicas, ora a eficácia do instrumento de ensino. O desempenho dos alunos é apresentado nas produções tanto de forma qualitativa quanto quantitativa.

O desempenho quantitativo dos alunos é verificado por meio da aplicação de testes e exercícios, realizados antes e após a utilização do lúdico, ou por meio da comparação da nota de turmas que desenvolveram a proposta com uma turma que não participou, como exemplo:

A avaliação da aprendizagem dos alunos foi baseada na análise dos questionários, antes e após a aplicação do jogo. Percebeu-se que houve um aumento de 34\% dos alunos que acertaram toda a atividade e $30 \%$ dos que acertaram $50 \%$. (PA005)

As notas obtidas ao final do bimestre ou o número de acertos de questões após a aplicação da atividade lúdica se tornam indicativos da eficácia da atividade na promoção da aprendizagem ou do instrumento de ensino. Essa forma de abordagem para avaliar a aprendizagem de uma relação entre sujeitos passa a se tornar uma relação entre coisas: as notas. Assim, a nota se torna o "Santo Graal", de forma que "não importa se ela expressa ou não uma aprendizagem satisfatória; ele quer a nota. Faz contas e médias para verificar a sua situação. É a nota que domina tudo, é em função dela que se vive na prática escolar" (Luckesi, 2008, p.24).

Já o desempenho qualitativo dos alunos é verificado através das características intrínsecas ao lúdico. Assim, a avaliação seja da eficácia da atividade lúdica ou da aprendizagem dos alunos é atribuída em função da resposta dos discentes ao lúdico. Nesse sentido, geralmente os autores enfatizam o envolvimento discente, o aumento do interesse, a motivação para execução da atividade, entre outros.

Observa-se que, nesses trabalhos, os autores destacam os resultados dos jogos em função dos aspectos emocionais e afetivos relacionados a sua aplicação. Para Rizzo (1996), tais aspectos são essenciais para o desenvolvimento da inteligência dos alunos, porque as emoções do jogo geram necessidades de ordem afetiva, que por sua vez, mobilizam o aluno em determinada direção com o objetivo de obter o prazer proporcionado pela atividade. Segundo a autora o interesse despertado por qualquer atividade lúdica, "produz como resposta o empenho de forças, ação intencional em direção ou propósito, fato essencial para produzir a construção de esquemas racionais, gradativamente mais aperfeiçoados" (Rizzo, 1996, p.40) e assim a construção da inteligência dos alunos.

Referente aos trabalhos que realizam uma análise qualitativa dos resultados encontram-se também textos que apresentam uma avaliação da aprendizagem em função da observação de seu desenvolvimento, conforme podemos verificar no trecho a seguir:

Os alunos demonstraram grande interesse pelo conteúdo abordado, demonstrado no decorrer das reuniões realizadas [...] Percebeu-se que os alunos se mostraram ansiosos e interessados em explicar cada um dos seus trabalhos [...] Os professores envolvidos notaram que houve melhora dos alunos quanto a participação em sala de aula e em 
relação ao entendimento de conceitos [...] (PA214)

Esses trabalhos exploram a relação entre o lúdico e os sujeitos envolvidos na situação proposta, ou seja, a interação entre os professores e os alunos e o desenrolar da atividade lúdica. Em tais produções, verificamos reflexões quanto à relação professoraluno, ao aspecto disciplinar, às dificuldades de aplicação, à motivação e participação discente, entre outros.

É interesse observar que a discussão da aprendizagem da química se dá, em sua maioria, por meio da relação 'jogo-nota' ou jogo-envolvimento', ou seja, baseada na aprendizagem por desempenho quantitativo ou lúdico. Nesse sentido, relatam uma melhoria da aprendizagem por meio das notas obtidas em testes após a aplicação das atividades lúdicas em comparação a testes anteriores. Há, também, aqueles que apresentam uma avaliação da aprendizagem em termos qualitativos, destacando o interesse proporcionado pela atividade, deixando subtendido, na maioria dos trabalhos, a motivação do lúdico para o estudo. Porém, ao se falar em notas, o que significa afinal esse valor atribuído ao aluno? O que ele indica para o processo de ensino, o que sinaliza quanto à aprendizagem do aluno? E a motivação proporcionada pelo lúdico é reflexo de que ocorreu uma aprendizagem?

Para Luckesi (2008), o que efetuamos na escola é um ato de verificação e não de avaliação da aprendizagem, sendo sua utilidade apenas classificar o educando, expressando sua aprovação ou reprovação, não se obtendo por meio dessa resultados mais significativos para a melhoria da qualidade ou do nível de aprendizagem dos educandos. A média obtida revela somente "o enquadramento do educando a partir de posicionamentos estáticos e autoritários a respeito da prática educacional" (Luckesi, 2008, p.36), não significando que o educando manifestou uma melhor e mais adequada aprendizagem, apenas que, ao final de um semestre ou bimestre letivo, está aprovado ou reprovado.

Para o autor, é necessário modificar a prática da avaliação escolar de classificatória para diagnóstica e dessa forma, assumi-la "como um instrumento de compreensão do estágio de aprendizagem em que se encontra o aluno, tendo em vista tomar decisões suficientes e satisfatórias para que possa avançar no seu processo de aprendizagem" (Luckesi, 2008, p.81). Nesse sentido, compreender a aferição apenas como momento de observar se o processo educacional está ocorrendo com a qualidade que deveria ter. Assim, como subsidiário da condução da ação, ao possibilitar compreender os avanços, limites e dificuldades dos educandos para atingir os objetivos de ensino.

Esses questionamentos nos levam a refletir sobre a aprendizagem propiciada pela utilização do lúdico. Tanto o desempenho quantitativo quanto o caráter lúdico expressam um aspecto dessa aprendizagem. Porém o que nos incomoda na escrita das produções é o posicionamento adotado pelos autores ao apresentar somente esses fatores na avaliação da aprendizagem do aluno. Verificou-se, na abordagem realizada, uma carência referente a uma discussão que envolva ou utilize discursivamente algum conceito de química. Seria interessante relatar a aprendizagem da química, mesmo que 
utilizando notas ou as características lúdicas, entretanto, expressando a aprendizagem do conceito evidenciando, respectivamente, como essa resultou no valor apresentado ou de que forma as características intrínsecas ao lúdico levaram a determinada aprendizagem. Nesse sentido, mostrar como o lúdico propicia a aprendizagem da química, isto é, nos momentos da aplicação em que se verifica a construção do conhecimento como se dá esse processo de apreensão da química ao manipular ou utilizar o lúdico.

Não há preocupação em descrever como se estabelece o diálogo entre o lúdico e o conceito de química, como se dá essa relação ou como foi averiguado sua influência na aprendizagem. Isso se torna preocupante na medida em que poucas discussões relatam 'quimicamente' a aprendizagem obtida com a atividade. Por 'quimicamente' queremos dizer que observamos pouca exploração nos trabalhos da relação conceito de química e lúdico. Os trabalhos se utilizam do lúdico para o ensino e a aprendizagem de conceitos da química, mas não expressam por escrito como se dá essa relação, como ela ocorre, como verificaram que a partir dos jogos e das atividades lúdicas os discentes aprenderam ou foram apresentados a disciplina de química, sua linguagem e simbologia.

Nos exemplos a seguir, podemos observar a função do lúdico da elaboração, ou revisão dos conceitos de química: Assim, nos trechos apresentados uma discussão sobre a aprendizagem que a atividade propicia, expressando a forma como os alunos vão assimilando determinados conceitos e os momentos lúdicos associados:

As plaquinhas com os elementos foram confeccionadas a partir de CD, papel A4 e caneta, utilizando fita adesiva dupla face para prega-las no quadro [...] Foram chamadas duplas para o quadro, onde pegaram o papel para saber qual seria a molécula e com isso procuraram os elementos correspondentes a eles e colaram no quadro, fizeram as suas ligações e expuseram a sua polaridade [...] Para explicar de modo correto a molécula sorteada, os alunos relembraram o conteúdo de ligações químicas e eletronegatividade [...] o lúdico teve uma grande contribuição para o esclarecimento do assunto, os alunos tiravam todas as dúvidas, onde eles próprios se ajudavam para o esclarecimento. (PA248)

Outro fator importante é que os alunos interrogaram o professor sobre a quantidade de ferro existente em uma barra, considerando-se que os mesmos estavam simulando uma liga de um metal. Essa pergunta surgiu porque eles contaram quantas pessoas estavam participando da simulação e fizeram uma extrapolação da analogia para a realidade para saber o quanto de unidades de ferro são necessárias para compor uma liga de ferro. A partir desta pergunta, a professora pôde discutir conceitos de massa molar e número de mol. Os alunos poderiam por exemplo, calcular a quantidade de átomos de um metal, existente em $0,5 \mathrm{~kg}$ de uma barra de níquel. (PA089)

No trecho da primeira atividade percebe-se seu desenvolvimento associado à revisão do conceito de polaridade. Mostra que, através da manipulação do material na atividade lúdica, ao colar no quadro as plaquinhas de $\mathrm{CD}$, os alunos foram elucidando as estruturas das moléculas e discutindo por meio da disposição dessas plaquinhas o conceito de polaridade. Já na segunda atividade, observa-se que a atividade lúdica instigou a busca pelo conhecimento químico. A partir da analogia realizada para a 
ligação metálica, os discentes questionam a quantidade de matéria presente no material, assim, possibilitando o ensino do conceito e a aprendizagem dos conceitos de massa molar e número de mol.

Quanto aos trabalhos que exploraram a relação entre o lúdico e o conceito de química, observamos que as produções publicadas na forma de trabalhos completos ou artigos apresentaram uma discussão dos resultados mais elaborada do que as produções em formato de resumo. Nos trabalhos em que há espaço disponível para discussão, alguns autores exploraram melhor a relação entre o lúdico e o conceito de química.

Verificou-se que muitas produções apresentam propostas interessantíssimas, ricas em possibilidades pedagógicas. Pela descrição, observamos que sua aplicação possibilita inúmeras abordagens e diversas formas de desenvolvimento do conteúdo de química. Entretanto, ao socializá-las com a comunidade acadêmica, a escrita do trabalho não expressa a riqueza da atividade desenvolvida, essa não é abarcada na forma de explorar discursivamente os resultados e a discussão da proposta apresentada. Observamos que, de uma forma geral, há dificuldade em se expressar, na escrita, a análise do trabalho desenvolvido.

Esse aspecto referente à escrita das produções se reflete sobre a visão que se tem do campo de pesquisa. A forma de se comunicar quanto ao estudo do assunto e o direcionamento abordado reflete o nível/grau de maturação teórica e metodológica do campo. Por isso, nos preocupamos com algumas formas de se expressar verificada nas produções, principalmente com relação à maneira como os autores finalizam seus trabalhos, apresentando suas conclusões sobre o lúdico e sua influência no ensino. Por exemplo, repetem-se bastante nas produções frases do tipo "resultado satisfatório", "eficaz ao que esperava", mas, realmente, o que essas expressões indicam, quais afirmações implícitas acompanham esses enunciados? O que se quer dizer por satisfatório e eficaz: satisfatório em que e, o que se esperava, nesse caso, qual o parâmetro que permite fazer essas afirmações?

Com os aspectos elencados queremos dizer que verificamos nos trabalhos frases tais como: "o jogo teve aceitação total pela turma", "melhorou o desempenho", "aumentou o interesse", "envolveu os discentes", "é legal", "é bom", "é motivador", entre outras, contudo, mostrando-se vazias em sua relação com o conceito de química e necessitadas de significado no processo de ensino e aprendizagem. Tais aspectos são encorajadores ao futuro professor que planeje se utilizar do lúdico em sua sala de aula, mas mantendo-se a discussão apenas nesse nível, além de não se explorar o potencial do lúdico para o Ensino de Química, estabelecemos, em nossos trabalhos, discussões 'vazias' e submetemos o campo de pesquisa a produções com pouca validação face a outros campos, dada sua baixa densidade teórico-metodológica.

Para a avaliação da eficácia da atividade lúdica como estratégia de ensino, os autores apresentam tanto o desempenho quantitativo dos discentes, como expresso anteriormente, quanto uma análise de sua aceitabilidade. Para averiguar a eficácia da proposta, é avaliado seu potencial pedagógico e aceitabilidade. A partir desses 
parâmetros, os autores validam a proposta ou o recurso lúdico utilizado.

Quanto ao potencial pedagógico, verificamos que esse é atribuído por meio das notas ou do número de acertos obtidos em testes após sua aplicação. Nesse sentido, esses valores expressam a função didática da atividade, ou seja, o conteúdo abordado pelo lúdico é determinado pela resposta quantitativa do discente em um teste pontual. É importante um retorno quantitativo da atividade, mas, pode somente este expressar o potencial pedagógico do recurso lúdico utilizado? Pode a nota significar aprendizagem efetiva do conteúdo ou conceito trabalhado? Em nossa reflexão não queremos discutir a importância do aspecto quantitativo, mas sim ressaltar o problema verificado na escrita de várias produções em que muitas vezes apenas este viés é considerado.

Cavalcanti (2011), em sua pesquisa, apresenta as possibilidades pedagógicas no uso do lúdico no ensino. Durante a realização da atividade lúdica, em meio à descontração e liberdade da atividade, o professor pode identificar nas ações dos estudantes o que sabem ou não, suas falhas conceituais, detectar erros e, sem tensão, corrigi-los durante a atividade. Segundo o autor, o lúdico ainda propicia que o docente (re)avalie suas aulas e (re)pense sua prática, buscando melhorá-la. Sendo o lúdico, como estratégia de ensino, um recurso que permite inúmeras possibilidades pedagógicas, sentimos a ausência desses aspectos ao se validar o potencial pedagógico da atividade.

Uma discussão em função apenas de uma nota pontualmente atribuída ou da percentagem de acertos não expressa a interação do aluno com o lúdico, não expõe como este recurso possibilitou a troca de conhecimentos entre os discentes, de que forma a competição entre os grupos impulsionou uma discussão sobre os conteúdos químicos, a maneira como os erros dos discentes foram reconhecidos, discutidos e corrigidos ou mesmo como a atividade estimulou ao estudo de algo. $\mathrm{O}$ que queremos dizer é que um número apresentado como resultado não é (ou pode não ser) suficiente para descrever o potencial pedagógico da atividade, e muito menos expressar a aprendizagem obtida, que vai além do aspecto cognitivo, englobando por meio das interações estabelecidas o afetivo, social, emocional e psicológico.

A avaliação da eficácia da atividade lúdica por meio de sua aceitabilidade, também é apresentada de forma quantitativa e qualitativa. Esta é averiguada através de questionários com questões objetivas e discursivas sobre a aplicação do lúdico, tais como se gostou do jogo, se a proposta é interessante, se aprendeu com o jogo, se este influenciou a aprendizagem da química, se o professor deveria trabalhar com mais propostas deste tipo, entre outros. A resposta a estas questões é quantificada, fornecendo ao pesquisador um percentual da aceitabilidade discente à proposta apresentada.

Já a avaliação da aceitabilidade discente torna-se importante, à medida que se pensa na definição de um jogo educativo conforme proposto por Kishimoto (2009). Se a atividade lúdica não possui atratividade para o aluno, perde seu potencial para motivar a participação espontânea do discente na estratégia pedagógica proposta. A função lúdica proposta não se encontra em equilíbrio com a função didática. Cabe ressaltar que se a atividade proposta não apresenta ludismo ao aluno, se utilizada, haverá aproveitamento 
apenas da função educativa, tornando-se somente um material instrucional. Se um material lúdico é levado para a sala de aula, é porque a proposta docente envolve o divertir. Se a atividade não apresenta tal característica, ela deve ser repensada de forma a desenvolver sua função lúdica.

Verificamos trabalhos em que a aceitabilidade discente é vinculada à aprendizagem ou mesmo se torna uma forma de avaliação de que o aluno aprendeu o conteúdo apresentado. Em tais trabalhos, a expressão "você gostou" se torna sinônimo de "aprendeu" e "resultados satisfatórios". Novamente questionamos o que seriam resultados satisfatórios e como pode ser satisfatório para a aprendizagem o discente só gostar da atividade proposta. Conforme apresenta Messeder Neto (2012) é muito fácil que, no fim de uma atividade lúdica, o interesse do aluno seja pelo recurso e não pelo conteúdo científico, por isso, é necessário que se compreenda que o jogo está direcionado a um motivo maior, a aprendizagem: "devemos começar como jogo, mas devemos chegar a atividade principal do estudo" (Messeder Neto, 2012, p.53). Deve-se compreender que a utilidade do "gostar" está no motivar o discente para o estudo

O gostar é o início para que o professor possa desenvolver sua proposta pedagógica. Assim, segundo Messeder Neto (2012) a atividade lúdica tem que ser o ponto de partida e não o ponto de chegada da aprendizagem, de forma que ao fim do processo o interesse do aluno seja pelo conteúdo e não pela atividade que o introduziu, "o professor precisa agir de modo que o jogo vire motivo secundário e ao fim do processo o estudo tornese atividade, uma vez que o motivo passa a ser o próprio ato de estudar e conhecer a realidade" (Messeder Neto, 2012, p.53).

Não podemos confundir a aceitabilidade discente das características lúdicas da atividade como indicativo do potencial pedagógico da proposta. Uma coisa é o aluno se interessar pela atividade, outra é esta resultar em aprendizagem, ou mesmo, ser um material que apresenta uma proposta pedagógica adequada em termos de conteúdo, nível de dificuldade, entendimento das regras. Assim, o gostar da atividade lúdica não significa que ocorreu aprendizagem, bem como que esta seja um bom instrumento de ensino.

Ao perguntar para um aluno se ele gosta de uma atividade extraclasse ou que fuja de sua rotina habitual de giz e quadro-negro, geralmente, a resposta é sim. Qualquer novidade que o professor leva para sala de aula resulta em uma melhoria no processo de ensino e aprendizagem quando comparado a suas aulas habituais. Pois, a novidade proposta desperta o interesse do aluno, instiga sua curiosidade e motiva sua participação na atividade desenvolvida. Portanto, quando questionamos o gostar do discente referente ao método utilizado e logo relacionamos a melhoria da aprendizagem a resultados satisfatórios no processo de ensino, não acrescentamos absolutamente nada à discussão, porquanto, já sabemos que este apresentará algum efeito positivo no ensino.

Para Brougère (2002) "a dimensão educativa pode acompanhar toda a atividade, mas isto depende, naturalmente, do tipo de experiência realmente vivenciada por uma pessoa face a essa atividade", essa experiência que o indivíduo vivencia que pode ter o 
efeito educativo. Assim, seria interessante refletir porque utilizar o lúdico, se com outros métodos também se obtém resultado positivo. Questionar sua viabilidade e a frequência de sua utilização em sala de aula, ou mesmo se é adequado para o ensino de qualquer conteúdo ou conceito químico. Nesse sentido, se perguntar então em que o lúdico difere de outras propostas e por que o utilizar em nossa sala de aula, que efeito educativo pode ter essa experiência lúdica ao aluno.

\section{Natureza dos Trabalhos - Fundamentação Teórica}

Uma característica observada na maioria dos trabalhos é sua débil relação com a fundamentação teórica sobre o lúdico no Ensino de Química. Verificou-se que a maioria dos trabalhos apresenta pequenas discussões ou apenas citam o lúdico. Às vezes, essas falas se restringem a uma breve revisão bibliográfica, apresentação das características intrínsecas ao lúdico ou definição de jogo educativo. Excetuando-se as dissertações e as teses, as produções apresentam uma escrita pouco elaborada sobre o referencial teórico para jogo, brincadeira ou lúdico. Entretanto, tal fato não significa que a produção não apresente embasamento teórico em suas referências bibliográficas, apenas que em sua escrita este é pouco desenvolvido.

Cabe ressaltar, que na busca realizada compreendemos como embasamento teórico sobre o lúdico não apenas produções sobre teorias filosóficas, psicológicas ou pedagógicas sobre o jogo ou brincar. Foram consideradas em nossa análise as produções que apresentavam propostas/aplicações de jogos para o Ensino de Química ou de outra disciplina. No total de 376 trabalhos publicados em periódicos e eventos da área, foram encontradas 871 citações bibliográficas referenciando a 293 produções, sendo essas publicações em formato de livro, capítulo de livro, artigo, resumo e trabalho completo publicado em evento.

Os artigos da QN não apresentam referencial teórico sobre o lúdico. Neste periódico, somente um artigo que apresenta em suas referências uma revisão citando trabalhos publicados na Journal Chemical Education que utilizaram jogos para o Ensino de Química. Na QNESC e ReBEQ, verificou-se que a maioria dos artigos apresentam um texto sobre jogos ou lúdico, resumidos em breves parágrafos ou em subtítulo (no caso de alguns artigos). Outra característica dessas produções é que apresentam uma revisão de trabalhos publicados sobre o ensino de algum conteúdo de química utilizando o lúdico. $\mathrm{Na}$ ReBEQ todos os artigos apresentam em sua bibliografia referenciais sobre o lúdico, já na QNESC, 4 artigos não fazem referências.

Analisando os referenciais utilizados pelos autores nos periódicos e nos trabalhos publicados em evento, verificamos que 114 trabalhos (do total de 376) não apresentam referenciais bibliográficos sobre jogo, brincadeira, lúdico ou brincar, correspondendo a $30,3 \%$ das produções. Nessas produções, observamos que há referenciais sobre teorias de aprendizagem, formação docente, contextualização, metodologia, conteúdo química, entre outros. Mesmo não utilizando um teórico que trate do lúdico no ensino, essas produções fazem referência aos jogos ou ao lúdico. 
O fato de 30,3\% das produções não apresentarem referenciais nos faz pensar tanto sobre a origem de tais trabalhos quanto sobre o reflexo para o campo de pesquisa do lúdico em Ensino de Química. Com relação ao primeiro caso, nos questionamos se esses trabalhos originalmente tiveram como intencionalidade se integrarem ao campo de pesquisa sobre o lúdico, ou se sua proposta de ensino veio ao encontro do campo de pesquisa em estudo. Por não apresentarem nenhum referencial sobre o lúdico, inferimos que nesses, o lúdico representa somente o 'meio' que os autores utilizaram para atingir seus objetivos educacionais, destacando que esse 'meio' poderia ter sido qualquer outro instrumento de ensino, porém, por casualidade, o 'meio' escolhido pelo autor foi o lúdico. É como se tais trabalhos fossem adendos ao campo de pesquisa.

O reflexo principal dessas produções sobre o campo de pesquisa é evidenciar uma fragilidade teórica e metodológica do campo. Podemos inferir, que se tais propostas são submetidas tanto em periódicos quanto em eventos e aprovadas sem referenciais sobre o lúdico, é porque este não é considerado necessário para o assessor que revisou o trabalho. Se a ausência de um referencial sobre o campo não é detectado, sinaliza que esse não é reconhecido como campo de pesquisa entre a comunidade acadêmica.

A comunidade acadêmica é extremamente importante para reconhecimento e desenvolvimento de um campo de pesquisa. Para Ludwik Fleck a construção do conhecimento ocorre de maneira coletiva e é influenciada pelos contextos históricopsico-culturais, assim como, nos conhecimentos já estabelecidos. Nesse processo, considera que a relação entre os indivíduos ocorre tanto dentro de um coletivo de pensamento quanto entre coletivos de pensamentos na comunidade acadêmica, por meio da circulação intercoletiva e intracoletiva entre as ideias e entre os círculos ao qual o cientista pertence (Delizoicov et al. 2002; Löwy, 1994; Milaré, 2013).

Para Ludwik Fleck os indivíduos compartilham práticas, concepções, tradições, normas e linguagens formando um coletivo de pensamento. Para o autor, o coletivo de pensamento pode ser compreendido como uma unidade social da comunidade de especialistas em determinada área. Ainda segundo o autor, uma simples união entre os indivíduos não forma esse coletivo, para tal é necessário que eles compreendam de uma mesma maneira o objeto de conhecimento desse coletivo. A forma de lidar com o objeto do conhecimento é denominada de estilo de pensamento. Esse direciona, de forma quase sempre inconsciente, o modo como o integrante desse coletivo de pensamento concebe, pensa, percebe e age sobre seu objeto de conhecimento.

Segundo Löwy (1994), como exemplo, Ludwik Fleck compara a forma que bioquímicos e epidemiologistas podem abordar os critérios de avaliação de uma dada bactéria, nesse caso Streptococcus haemolyticus, para o primeiro em sua definição desejaria excluir todos os casos duvidosos. Já o segundo por conta do perigo de patógenos potenciais incluiria em seus testes não apenas colônias de bactérias com todas as características típicas do exemplo citado, mas também aquelas que possuam algumas das características. Para Ludwik Fleck, as duas definições são parcialmente incomensuráveis, uma não é mais 'verdadeira' que a outra, a 'verdadeira’ definição não 
tem sentido fora de seu contexto, isto é, fora do "estilo de pensamento" do "coletivo de pensamento" que estamos pensando a questão.

Partindo desses princípios e a relação que se estabelece intra e entre os coletivos de pensamento, para Ludwik Fleck o diálogo entre a comunidade acadêmica ocorre através da comunicação entre os círculos esotérico e exotérico. O primeiro se refere aos especialistas de uma determinada área. Para o autor, ao redor desse círculo (especialistas) encontra-se o círculo exotérico, formado por leigos nessa área em questão. Ressalta ainda, que o círculo exotérico é extremamente importante para legitimação do círculo esotérico, pois a partir da confiança nos especialistas validam e legitimam o conhecimento destes.

Relacionando as ideias de Ludwik Fleck (Delizoicov et al. 2002; Löwy, 1994; Milaré, 2013) aos resultados obtidos, podemos considerar os autores que desenvolvem trabalhos em jogos e atividades lúdicas em Ensino de Química como os especialistas que compõem o círculo esotérico deste campo de pesquisa. Assim, observamos que um problema de nosso campo de pesquisa encontra-se no reconhecimento do círculo exotérico, tanto de nossos conhecimentos quanto de nossas práticas. Como dito anteriormente, se os referenciais que embasam o campo, não são reconhecidos como necessários pelos especialistas em Ensino de Química 'leigos' em nosso campo de pesquisa é porque este ainda não foi legitimado junto à comunidade. É necessário buscar a legitimação do campo entre os pares, sua consolidação no círculo esotérico, porém é essencial o reconhecimento do círculo exotérico. Nosso objeto de conhecimento ainda não obteve confiança dos especialistas em Ensino de Química, precisamos aperfeiçoar nossos trabalhos de forma que a temática abordada seja reconhecida em nosso círculo exotérico.

Com relação aos conteúdos desses referenciais, observamos que eles se dividem em obras que refletem sobre o jogo e a brincadeira (217) e sobre a utilização do lúdico no Ensino de Química (281). As produções que discorrem sobre aspectos teóricos do jogo abordam suas características filosóficas (obras de Joham Huizinga e Giles Brougère), psicológicas (os dois principais livros de Lev Vygotsky, e uma vasta citação de obras de Jean Piaget) e pedagógicas (o trabalho da professora Tizuko Kishimoto).

Uma característica do embasamento teórico-metodológico do lúdico nas produções de Ensino de Química relaciona-se à sua função no texto. Verificou-se que, geralmente, utilizam-se referenciais para destacar a importância de se utilizar jogos, validar a atividade proposta no trabalho, ressaltar que é uma estratégia de ensino que apresenta bons resultados pedagógicos ou para exemplificar sua utilização no Ensino de Química. Nos resumos, poucas vezes são utilizados referenciais para referendar os resultados.

Por outro lado, nos artigos e trabalhos completos, verifica-se que ocorre uma validação por funcionalidade. Os autores referendam seus trabalhos por comparação com comportamentos similares em trabalhos que aplicaram atividades lúdicas. A validação por funcionalidade pode ser observada também no embasamento teórico apresentado na introdução dos textos, em que, na maioria das vezes, observou-se que, ao invés de 
utilizar referenciais para embasar teoricamente ou metodologicamente o uso do lúdico no ensino, são apresentadas propostas baseadas nos mesmos que resultaram em um processo de ensino e aprendizagem significativo. As produções apresentam referenciais no intuito de validar a prática pedagógica proposta ao apresentar um trabalho em que a atividade lúdica utilizada resultou em um método de ensino eficaz.

Um aspecto pouco observado nas análises é uma discussão dos resultados baseada no diálogo com teóricos do jogo. Mesmo havendo abordagens antropológicas, psicológicas, sociológicas, filosóficas, entre outras, observa-se que o embasamento "teórico" tanto da discussão quanto da introdução do texto, encontra-se em aspectos metodológicos relativos à utilização e aplicação de jogos no ensino da química, destacando-se as ideias de Márlon H. F. B. Soares, Tizuko M. Kishimoto e Márcia B. da Cunha. Pode-se dizer que os "aspectos metodológicos" atualmente são o que compreendemos por "aspectos teóricos" do lúdico no Ensino de Química.

Outro aspecto que se reflete no campo de pesquisa sobre a temática encontrase no crescimento endógeno da área. Observou-se nas produções a predominância de trabalhos produzidos por uma mesma instituição, orientados pelo mesmo pesquisador, realizados pelo mesmo grupo de pesquisa. Este fato leva a dois aspectos negativos: a concentração da produção em determinadas regiões do país (principalmente no Sudeste e no Centro-Oeste) e na padronização da fundamentação teórica. A padronização advém da produção acadêmica estar relacionada a poucos grupos ou linhas de pesquisa, assim, havendo uma uniformização dos teóricos utilizados.

A endogenia é uma palavra derivada do grego que significa, de acordo com o Dicionário Michaelis (Weiszflog, 2004), um crescimento de dentro ou de uma camada interna, diz respeito a algo que, em sua formação ou constituição, possui início e se desenvolve por dentro, no interior. A endogenia na pesquisa pode ser caracterizada pela concentração de autores com a mesma orientação ideológica, com trabalhos publicados em um mesmo local, pela grande concentração de autores citados em poucos programas de pós-graduação, pelo excesso de autocitações ou citações do mesmo programa ou grupo, pela concentração de trabalhos publicados de uma mesma região, pelo pesquisador permanecer na instituição e se vincular ao grupo que o formou, entre outros aspectos (Braga \& Venturini, 2013; Caldas \& Tinoco, 2004; Costa, 2006).

Sendo a ciência uma construção humana, somente a partir do debate na comunidade acadêmica, nas ideias e opiniões divergentes, a produção poderá ser discutida e validada por pares. Apenas dessa forma pode-se pensar na estruturação do campo de pesquisa e em sua consolidação. A partir do momento em que há uma diversidade de pesquisas, variações de temas, há possibilidade de discussão e troca entre pares e, assim, produção do conhecimento. Se isso não ocorrer e a pesquisa ficar restrita a poucos pesquisadores, há um desenvolvimento endógeno do campo. Sendo os assuntos orientados apenas por uma perspectiva, há linearidade no pensar, não havendo divergências, e assim possibilidades de desequilíbrios e reestruturação do campo, que são fundamentais para seu desenvolvimento. Assim, com poucos pesquisadores 
participando do processo de pesquisa, corre-se o risco da área se atrofiar.

Segundo Caldas e Tinoco (2004), esses tipos de concentração excessiva seja relacionado a autores, programas, instituição ou região podem ameaçar a diversidade de referências da área, tornando-se um dos principais direcionadores de endogenia acadêmica. Essas práticas endógenas são indesejáveis no meio acadêmico, pois fornecem uma visão unilateral dos fenômenos, criam estagnação intelectual, não permitindo troca e renovação de ideias, não sendo uma prática saudável para o desenvolvimento científico. Por tais aspectos, nos inquieta perceber que o campo está se estruturando com práticas endógenas. Para que a área se desenvolva, é necessária uma participação maior de outros pesquisadores, para que haja diversificação na produção e, assim, diálogo, troca e permuta entre os pares.

A sistematização dos aspectos a serem observados em uma aplicação em forma escrita, pelos autores citados, levou à base teórica do campo tal qual a conhecemos hoje, permitindo tanto a fundamentação teórica dos trabalhos quanto a prática do professor em sala de aula. Entretanto, é necessário que o embasamento do campo se desenvolva. Isso não significa abandonar sua base metodologicamente estruturada, mas expandir os fundamentos teóricos e metodológicos do campo, relacionando-os a outras áreas do conhecimento. Pois, mesmo sendo um campo em formação, se as discussões permanecerem restritas a poucos pesquisadores e com apenas o direcionamento metodológico nas discussões, teremos grande chance de observar o atrofiamento da área.

\section{Considerações Finais}

O quadro geral apresentado mostra que esse campo de pesquisa ainda está relativamente no início. Temos uma quantidade relativa de produção sobre o lúdico em ensino de química crescente a cada ano, mas, para que se possa seguir caminho é necessário que nossas produções apresentem uma maior preocupação teóricometodológica. Desse modo, o campo poderá ser considerado como consolidado, ao invés de simplesmente como um campo que não apenas se apropriou de teorias e abordagens de outras áreas com tradição na pesquisa, podendo sustentar seu próprio corpo teórico. A partir de um processo de adequação de referenciais de outros campos, podemos conseguir um domínio das teorias transpostas para responder as perspectivas e problemas específicos deste campo. É primordial uma maior associação das produções com projetos de pesquisa, em especial, com programas de pós-graduação.

Com relação à escrita das produções, de forma geral observou-se uma dificuldade em explorar discursivamente os resultados da proposta realizada. Existem propostas muito interessantes, mas ao socializa-las com a comunidade acadêmica, o autor não consegue expressar a riqueza da atividade desenvolvida. Verificou-se também uma tendência a conclusões "vazias" sobre o lúdico e sua influência no Ensino de Química. Por exemplo, a utilização de frases do tipo "resultado satisfatório", "eficaz ao que esperava", sem que o significado dessas expressões ou os parâmetros que permitem fazer 
essas afirmações sejam explicitados.

Há também conclusões com frases estimulantes sobre o lúdico, como, por exemplo "o jogo teve aceitação total pela turma", "melhorou o desempenho", "aumentou o interesse”, "é legal”, “é bom”, entre outras. Tais aspectos são encorajadores ao futuro professor que planeje utilizar o lúdico em sua sala de aula, contudo, assim apresentadas mostram-se vazias em sua relação com o conceito químico a ser ensinado e sem significado no processo de ensino e aprendizagem. É necessário apresentar discussões mais fundamentadas, para não estabelecer discussões 'vazias' e submeter o campo de pesquisa a produções com pouca validação face a outros campos de pesquisa, dada sua frágil relação teórica e metodológica.

Visualizando o quadro geral das produções e as características que têm se destacado em seu desenvolvimento, compreendemos que o campo de pesquisa sobre o lúdico no Ensino de Química ainda está em formação. Nesse sentido, encontramos muitas lacunas a serem desenvolvidas, assim como muitos espaços a serem explorados. Por exemplo, faltam trabalhos em outros níveis de ensino que não o ensino médio e os conteúdos são sempre centrados em conceitos já amplamente discutidos, como tabela periódica e nomenclatura em química orgânica. Há uma quantidade extremamente grande de jogos sobre esses conceitos, apontando para a necessidade de se diversificar. A fundamentação teórica utilizada também não é ainda inovadora e não considera trabalhos da literatura internacional, ficando ainda restrita a poucos autores. Podemos ainda, destacar a forma de avaliação da atividade lúdica e da aprendizagem do aluno, a forma de expressar discursivamente a proposta realizada, entre outros.

Nessa perspectiva, estamos desenvolvendo a base teórico-metodológica do campo, de forma que para sua consolidação ainda faltam muitas discussões. Considerando os aspectos discutidos nesse artigo, os principais são a compreensão do potencial do lúdico e a importância e necessidade de sua exploração frente a discussões e aprofundamentos teóricos no ensino e na química.

\section{Referências}

Beltran, N. O. (1997). Idéias em Movimento. Química Nova na Escola, 5, 14-17.

Bogdan, R. C., \& Biklen, S. K. (1994). Investigação Qualitativa em Educação: uma introdução a teoria e métodos. Porto, Portugal: Porto Editora.

Braga, M. M. S., \& Venturini, A. E. J. F. (2013). Endogenia Acadêmica em um Programa de Pós-Graduação em Direito. In O. Mezzaroba, J. Q. Tavares Neto, \& S. A. Vasconcelos (Orgs.). Direito, educação, ensino e metodologia jurídicos. Florianópolis, SC: FUNJAB.

Brougère, G. (1998). Jogo e Educação. Porto Alegre, RS: Artmed.

Brougère, G. (2002). Lúdico e educação: novas perspectivas. Linhas críticas, 8(14), 5-27.

Caillois, R. (1990). Os jogos e os homens. Lisboa: Cotovia. 
Caldas, M. P., \& Tinoco, T. (2004). Pesquisa em Gestão de Recursos Humanos nos Anos 1990: um Estudo Bibliométrico. Revista de Administração de Empresas, 44(3), 100-114.

Cavalcanti, E. L. D. (2011). O lúdico e a avaliação da aprendizagem: possibilidades para o ensino e a aprendizagem de química. (Tese de Doutorado em Química). Universidade Federal de Goiás, Goiânia .

Costa, A. L. F. (2006). Publicação e Avaliação de Periódicos Científicos: Paradoxos da Classificação Qualis em Psicologia. (Dissertação de Mestrado em Psicologia). Universidade Federal do Rio Grande do Norte, Natal.

Delizoicov, D., Castilho, N., Cutolo, L. R. A., Daros, M. A., \& Lima, A. M. C. (2002). Sociogênese do conhecimento e pesquisa em ensino: contribuições a partir do referencial fleckiano. Caderno Brasileiro de Ensino de Física, 19(ESP), 52-69.

Ferreira, N. S. A. (2002). As pesquisas denominadas "estado da arte". Educação e Sociedade, 23(79), 257-272.

Fiorentini, D., \& Lorenzato, S. (2006). Investigação em educação matemática: percursos teóricos e metodológicos. Campinas, SP: Autores Associados.

Godoy, A. S. (1995). Introdução a pesquisa qualitativa e suas possibilidades. Revista de Administração de Empresas São Paulo, 35(2), 57-63.

Haddad, S. (2002). Educação de jovens e adultos no Brasil (1986-1998). Brasília, DF: MEC/Inep/ Comped.

Huizinga, J. (2000). Homo Ludens: o jogo como elemento de cultura (4a ed.). São Paulo, SP: Perspectiva.

Kishimoto, T. M. (2009). O jogo e a educação infantil. In T. M. Kishimoto (org.). Jogo, Brinquedo, Brincadeira e a Educação (12a ed.). São Paulo, SP: Cortez.

Löwy, I. (1994). Ludwik Fleck and the history of science today (Ludwik Fleck e a presente história das ciências). História, Ciências, Saúde - Manguinhos, I(1), 7-18.

Luckesi, C. C. (2008). Avaliação da aprendizagem escolar: estudos e proposições (19a ed.). São Paulo, SP: Cortez; 2008.

Ludke, M., \& Andre, M. (1986). Pesquisa em Educação: Abordagens Qualitativas. São Paulo, SP: Editora Pedagógica e Universitária.

Luna, S. V. (2011). Planejamento de pesquisa: uma introdução (2a ed.). São Paulo, SP: EDUC.

Megid Neto, J. (1999). Tendências da pesquisa acadêmica sobre o Ensino de Ciências no nível fundamental. (Tese de Doutorado em Educação). Universidade Estadual de Campinas, Campinas. 
Messeder Neto, H. S. (2012). Abordagem contextual lúdica e aprendizagem do conceito de equilíbrio químico: o que há atrás dessa cortina? (Dissertação de Mestrado em Ensino, Filosofia e História das Ciências). Universidade Federal da Bahia, Salvador.

Milaré, T. A pesquisa em Ensino de Química na Universidade de São Paulo: estudo das dissertações e teses (2006 a 2009) sob a perspectiva fleckiana. 2013. (Tese de Doutorado em Ensino de Ciências). Universidade de São Paulo, São Paulo.

Rizzo, G. (1996). Jogos Inteligentes: a construção do raciocínio na escola natural. Rio de Janeiro, RJ: Bertrand Brasil.

Rocha-Filho, R. C. (1996). Os fulerenos e sua espantosa geometria molecular. Química Nova na Escola, 4, 7-11.

Slongo, I. I. P., \& Delizoicov, D. (2005). Um panorama da produção acadêmica em ensino de biologia desenvolvida em programas nacionais de pós-graduação. Investigaçães em Ensino de Ciências, 11(3) 323-341.

Soares, M. H. F. B. (2016). Jogos e Atividades Lúdicas no Ensino de Química: uma discussão teórica necessária para novos avanços. Revista Debates em Ensino de Química, 2(2), 5-13.

Soares, M. H. F. B. (2013). Jogos e Atividades Lúdicas no Ensino de Química. Goiânia.

Teixeira, C. R. (2006). A concepção de avaliação educacional veiculada na produção acadêmica do Programa de Pós-Graduação em Educação: currículo (1975-2000). (Dissertação de Mestrado em Educação, Pontifícia Católica de São Paulo).

Weiszflog, W. (2007). Michaelis: moderno dicionário da língua portuguesa. São Paulo, SP: Melhoramentos. 
Edna Sheron da Costa Garcez

(1) http://orcid.org/0000-0001-6476-573X

Universidade Federal de Goiás

Instituto de Química

Laboratório de Educação Química e Atividades Lúdicas

Goiânia, Brasil

edna.sheron@gmail.com

Márlon Herbert Flora Barbosa Soares

(1) http://orcid.org/0000-0002-3273-8603

Universidade Federal de Goiás

Instituto de Química

Laboratório de Educação Química e Atividades Lúdicas

Goiânia, Brasil

marlon@ufg.br

Submetido em 25 de Feveiro 2015

Aceito em 2 de Março 2017

Publicado em 30 de Abril de 2017 